\title{
Synthesis of Double-Bridged Cofacial Nickel Porphyrin Dimers with 2,2'- Bipyridyl Pillars and Their Restricted Coordination Space
}

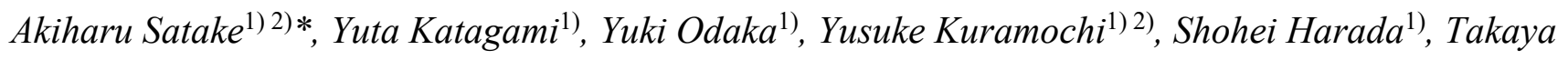
Kouchi $^{1)}$, Hajime Kamebuchi ${ }^{1) 3)}$, and Makoto Tadokoro ${ }^{1)}{ }^{3)}$

1) Graduate School of Science, Tokyo University of Science, 1-3 Kagurazaka, Shinjuku-ku, Tokyo 162-8601 (Japan)

2) Department of Chemistry, Faculty of Science Division II, Tokyo University of Science.

3) Department of Chemistry, Faculty of Science Division I, Tokyo University of Science. 

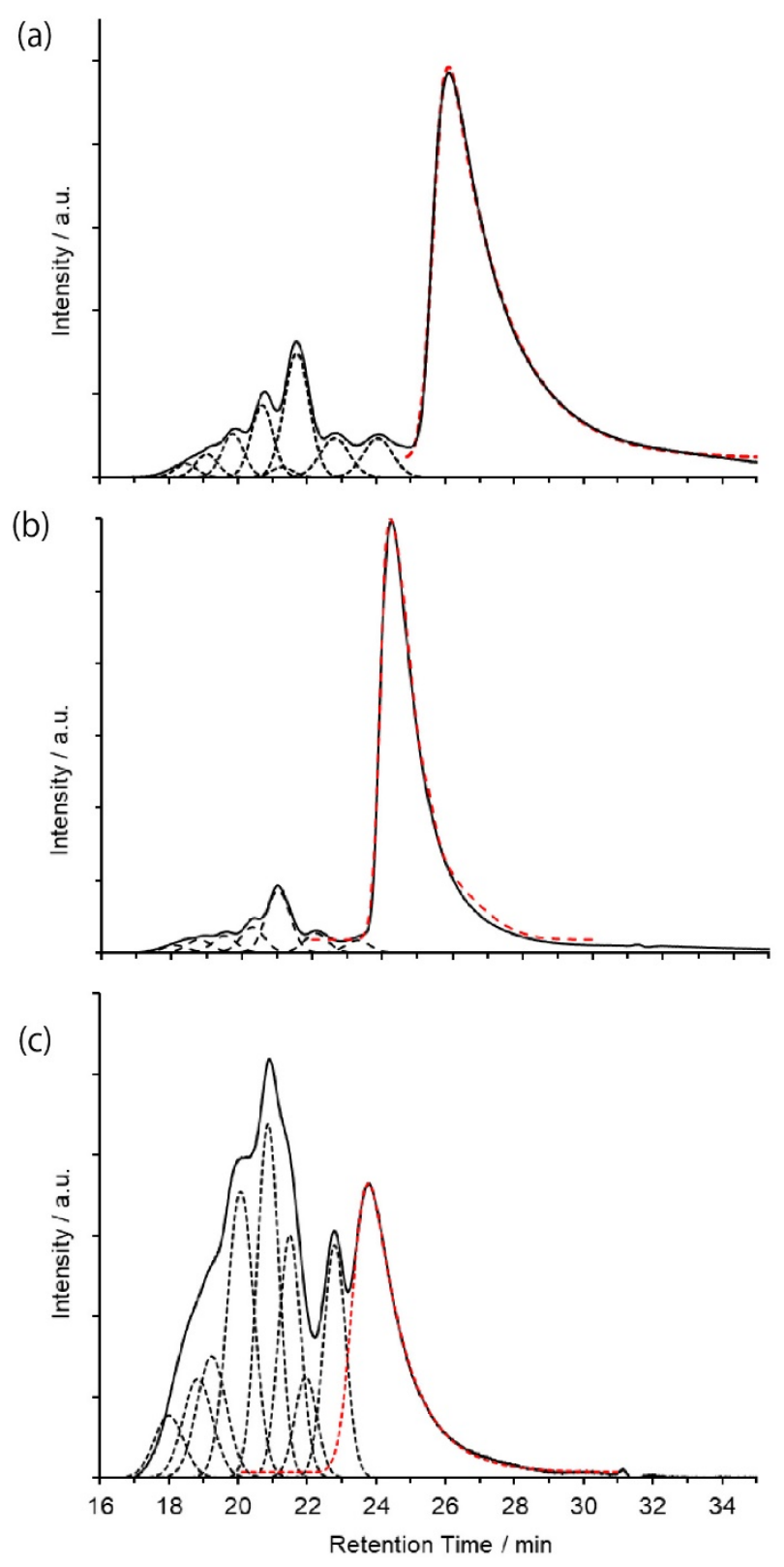

Figure S1. GPC charts (solid lines) of reaction mixtures from (a) $\mathbf{1}_{\mathbf{M e}}$, (b) $\mathbf{1}_{\mathbf{B u}}$, and (c) 1oc; GPC conditions: Tosoh G2500 $\mathrm{H}_{\mathrm{HR}} \times 2+\mathrm{G} 2000 \mathrm{H}_{\mathrm{HR}} \times 1$ (columns), pyridine (eluent), $1.0 \mathrm{~mL} / \mathrm{min}$ (flow rate), monitored at $536 \mathrm{~nm}$ in (a) and (b), and $563 \mathrm{~nm}$ in (c). Curve-fitting analyses show dotted lines, in which the red lines correspond to the cyclic porphyrin dimers. 
Table S1. Crystal data and structure refinement

\begin{tabular}{|c|c|c|c|}
\hline Compound & $20 \mathrm{Oc}$ & $2_{\mathrm{Bu}}$ & $2_{\mathrm{Bu}}-(\text { allylPd })_{2}$ \\
\hline Temperature (K) & 173 & 173 & 173 \\
\hline Crystal system & Triclinic & Monoclinic & Monoclinic \\
\hline Space group & $P-1(\# 2)$ & $C 2 / \mathrm{c}(\# 15)$ & $P 21 / n(\# 14)$ \\
\hline$a(\AA)$ & $13.725(8)$ & $20.464(8)$ & $16.4955(5)$ \\
\hline$b(\AA)$ & $14.935(8)$ & $21.756(8)$ & $16.5823(6)$ \\
\hline$c(\AA)$ & $15.352(9)$ & $27.647(10)$ & $29.2556(9)$ \\
\hline$\alpha(\mathrm{deg})$ & $92.577(7)$ & 90 & 90 \\
\hline$\beta(\operatorname{deg})$ & $109.984(6)$ & $98.453(4)$ & $105.4930(10)$ \\
\hline$\gamma(\operatorname{deg})$ & $99.780(7)$ & 90 & 90 \\
\hline$V\left(\AA^{3}\right)$ & $2896(3)$ & $12175(8)$ & $7711.6(4)$ \\
\hline$Z$ & 1 & 4 & 2 \\
\hline$D_{\text {calc. }}\left(\mathrm{mg} / \mathrm{m}^{3}\right)$ & 1.225 & 1.259 & 1.377 \\
\hline$F_{000}$ & 1132 & 4769 & 3246 \\
\hline Theta range for data collection $(<2 \theta)$ & 3.220 to $55.118^{\circ}$ & 2.748 to $50.052^{\circ}$ & 4.912 to $50.052^{\circ}$ \\
\hline Reflections collected & 15010 & 26227 & 83582 \\
\hline Independent reflections & $\begin{array}{c}12036 \\
{[\mathrm{R}(\text { int })=0.0311]}\end{array}$ & $\begin{array}{c}10653 \\
{[\mathrm{R}(\mathrm{int})=0.0743]}\end{array}$ & $\begin{array}{c}13588 \\
{[\mathrm{R}(\text { int })=0.0744]}\end{array}$ \\
\hline Final $R$ indices $[\mathrm{I}>2 \theta(\mathrm{I})]$ & $\begin{array}{c}\mathrm{R}_{1}=0.0729 \\
\mathrm{wR}_{2}=0.1988\end{array}$ & $\begin{array}{c}\mathrm{R}_{1}=0.0799 \\
\mathrm{wR}_{2}=0.2274\end{array}$ & $\begin{array}{c}\mathrm{R}_{1}=0.0543 \\
\mathrm{wR}_{2}=0.1393\end{array}$ \\
\hline$R$ indices (all data) & $\begin{array}{c}\mathrm{R}_{1}=0.1216 \\
\mathrm{wR}_{2}=0.2156\end{array}$ & $\begin{array}{c}\mathrm{R}_{1}=0.1471 \\
\mathrm{wR}_{2}=0.2820\end{array}$ & $\begin{array}{c}\mathrm{R}_{1}=0.0697 \\
\mathrm{wR}_{2}=0.1546\end{array}$ \\
\hline Goodness-of-fit & 1.105 & 1.008 & 1.031 \\
\hline
\end{tabular}


(a)

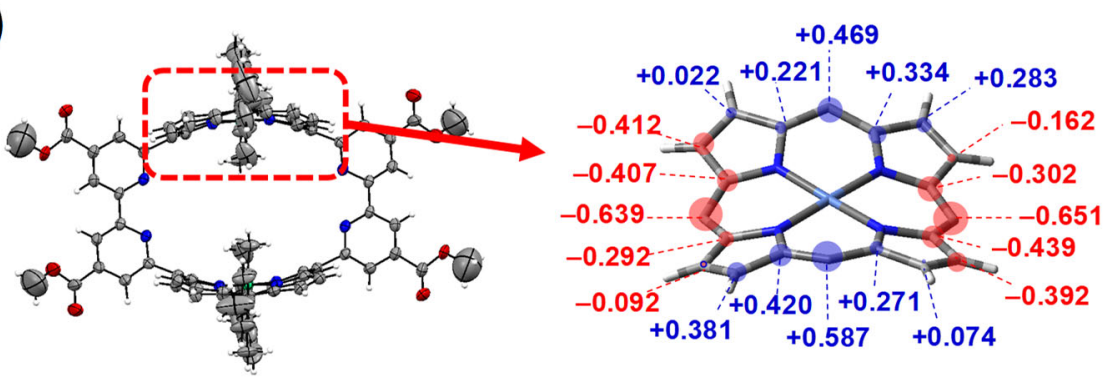

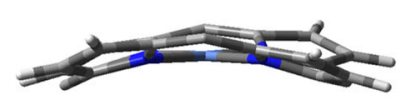

side view

(b)
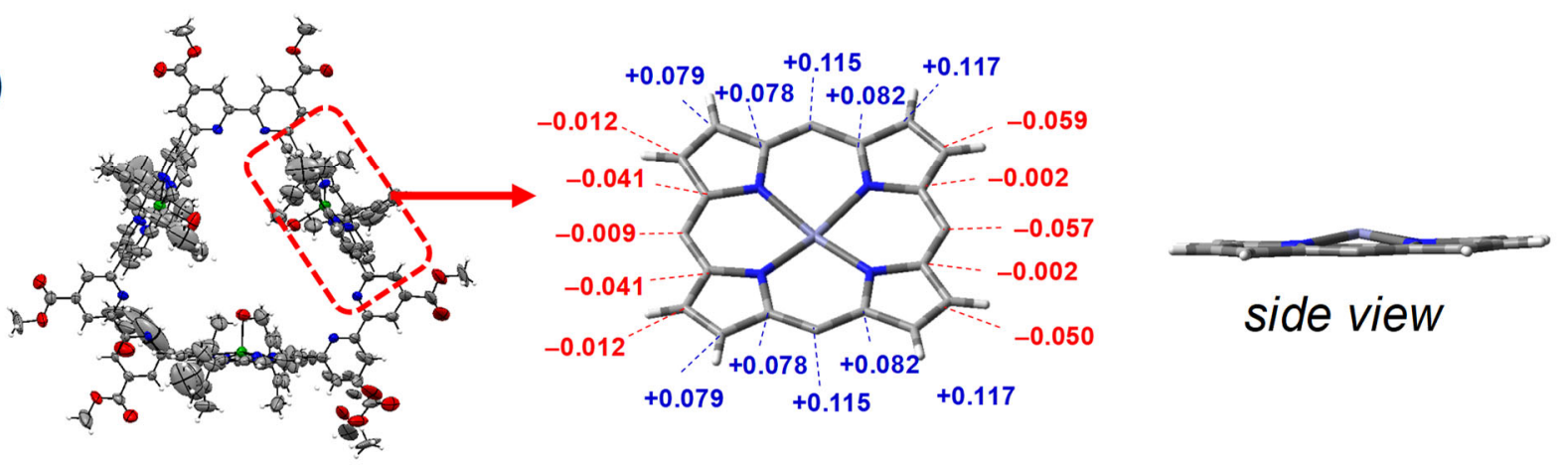

Figure S2. Crystal structures of (a) cyclic dimer of Ni(II) porphyrin $\mathbf{2}_{\mathbf{O c}}$ and (b) cyclic trimer of $\mathbf{Z n}$ (II) porphyrin $\mathbf{Z n -}$ $\mathbf{3}_{\text {Me. }}$ ORTEP views (left), the deviations of selected atoms (in $\AA$ ) from the $4 \mathrm{~N}$ mean planes (center), and side views of the porphyrin parts (right). 


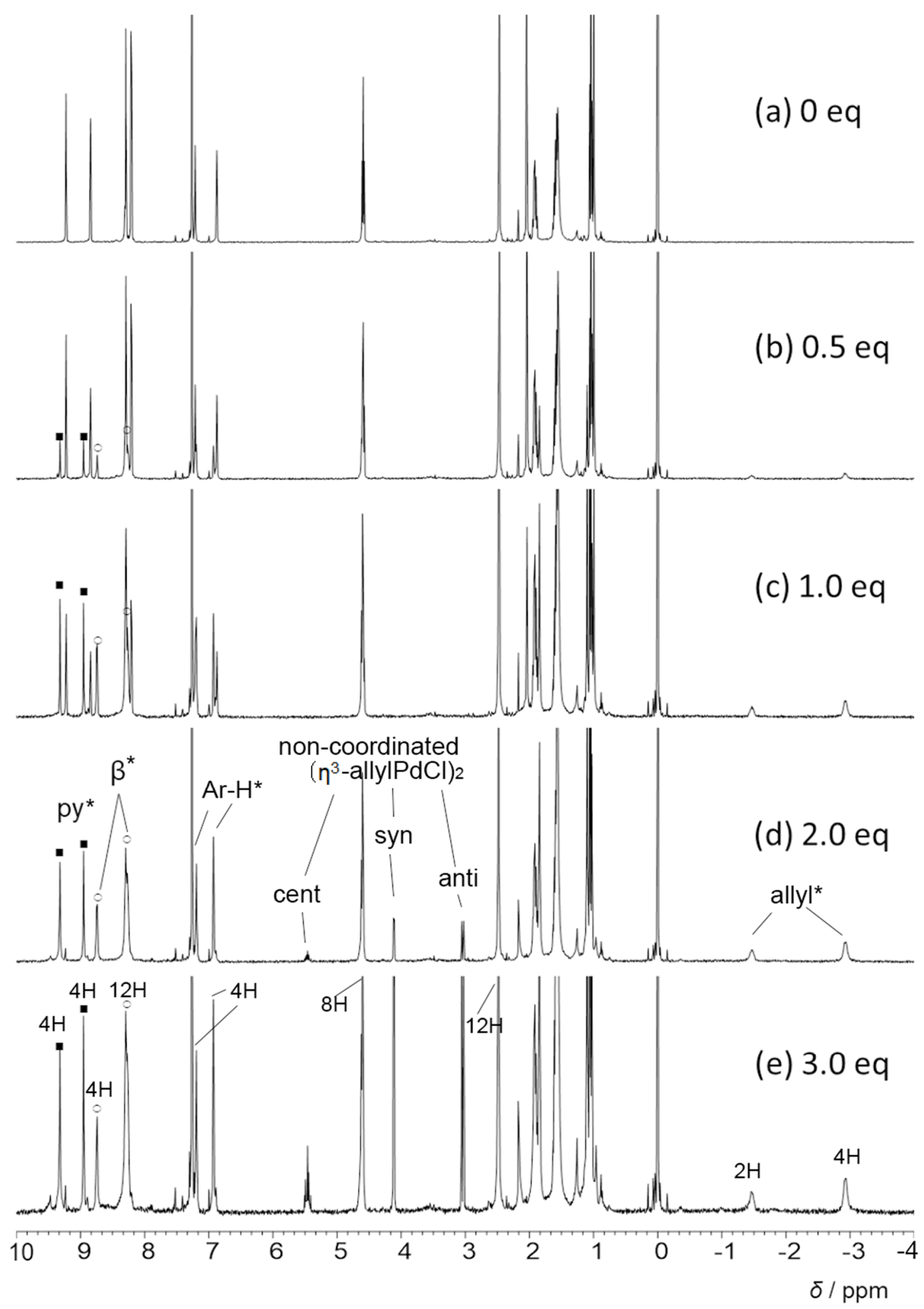

Figure S3. ${ }^{1} \mathrm{H}$ NMR (400 MHz) titration of cationic $\eta^{3}$-allylpalladium terafluoroborate complexes into $\mathbf{2}_{\mathbf{B u}}$ in $\mathrm{CDCl}_{3}$ at $24{ }^{\circ} \mathrm{C}$. (Enlargement between 10.0 and $6.5 \mathrm{ppm}$. See Figure 6.) From the top to the bottom: 0, 0.5, 1.0, 2.0, and 3.0 equiv. of the palladium species. 

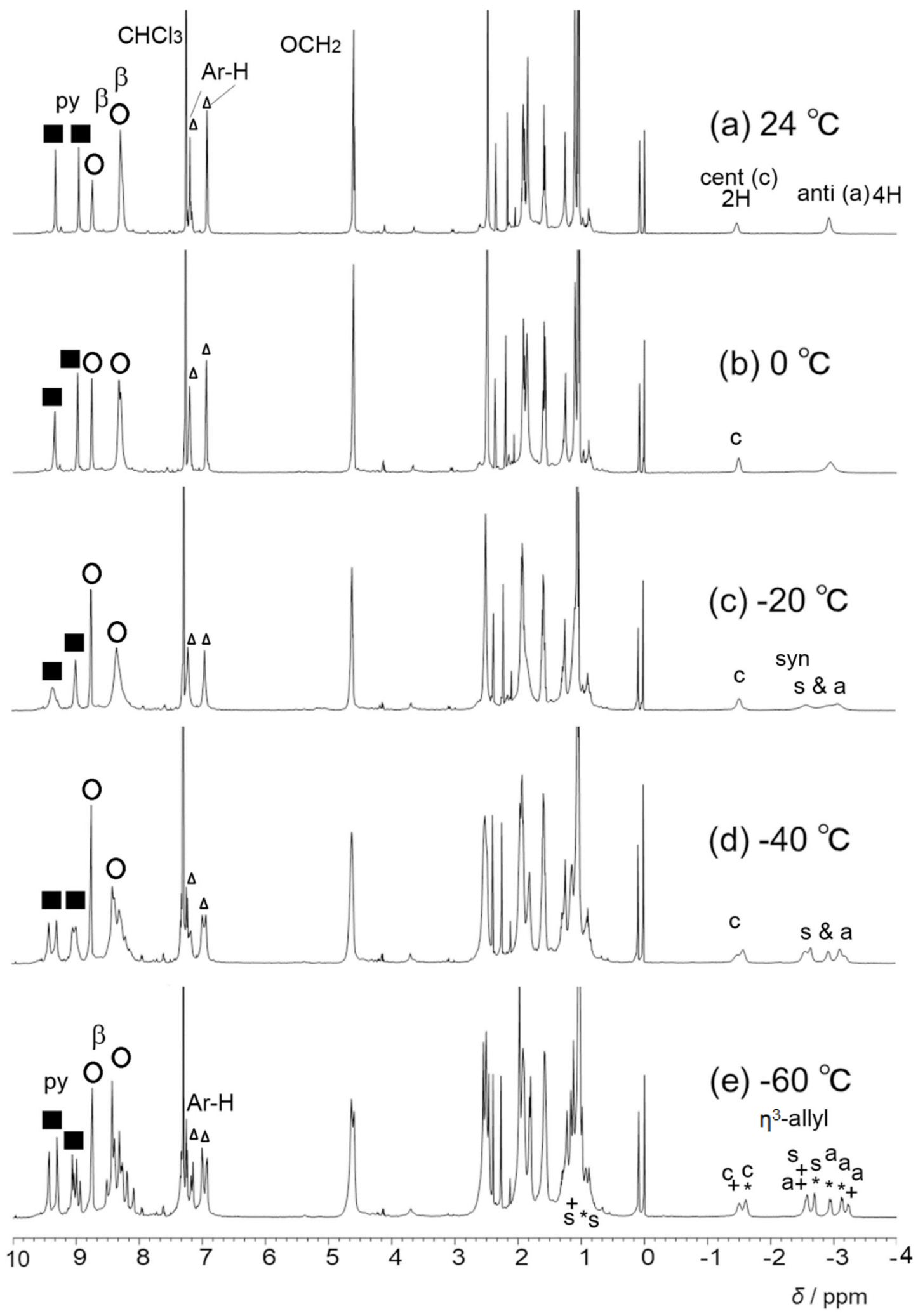

Figure S4. VT- ${ }^{1} \mathrm{H}$ NMR spectra $\left(400 \mathrm{MHz}, \mathrm{CDCl}_{3}\right)$ of a 2:1 mixture of cationic $\eta^{3}$-allylpalladium complexes and 2 $\mathrm{Bu}$. (a) $24{ }^{\circ} \mathrm{C}$, (b) $0{ }^{\circ} \mathrm{C}$, (c) $-20{ }^{\circ} \mathrm{C}$, (d) $-40{ }^{\circ} \mathrm{C}$, (e) $-60{ }^{\circ} \mathrm{C}$ 
(a)

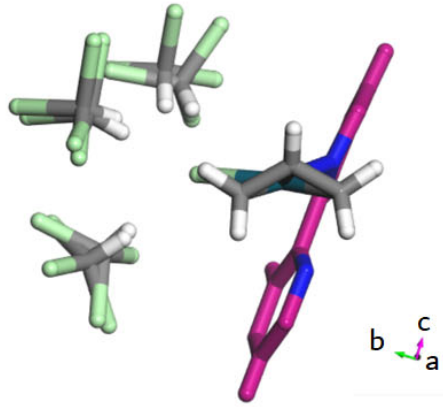

(b)

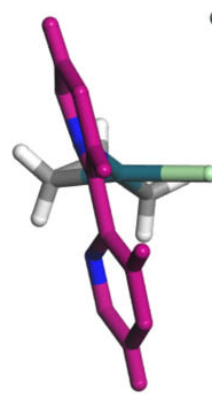

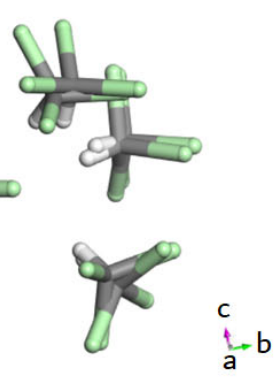

(c)

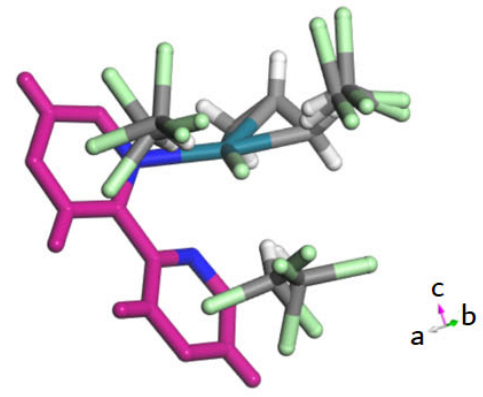

Figure S5. A $\eta^{3}$-allyl palladium chloride moiety in the molecular structure of $\mathbf{2}_{\mathbf{B u}}-(\text { allylPd })_{2}$ obtained by the XRD analysis. Purple colored atoms correspond to the 2,2'-bipyridyl part. The $\eta^{3}$-allyl palladium chloride and $\mathrm{CHCl}_{3}$ molecules are shown as light green (chlorine), green (palladium), blue (nitrogen), gray (carbon), and white (hydrogen atoms). (a) a front view of the $\eta^{3}$-allyl group, (b) (c) from other angles.

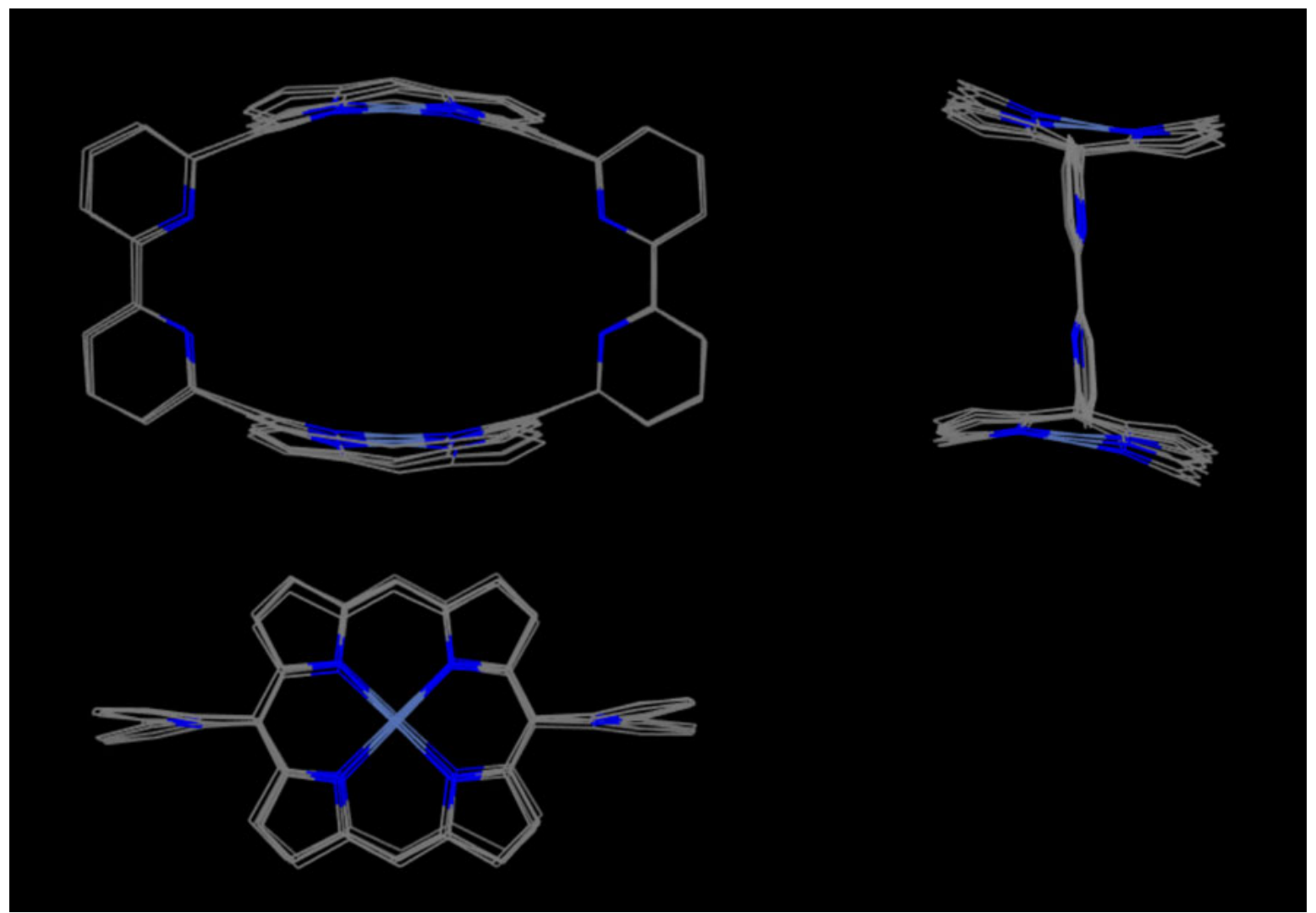

Figure S6. Macrocyclic frameworks composed of two porphyrin and two bipyridyl groups in $\mathbf{2}_{\mathrm{Oc}}, \mathbf{2}_{\mathrm{Bu}}, \mathbf{2}_{\mathrm{Bu}}-(\mathbf{a l l y l P d})_{2}$ (overlaid). 


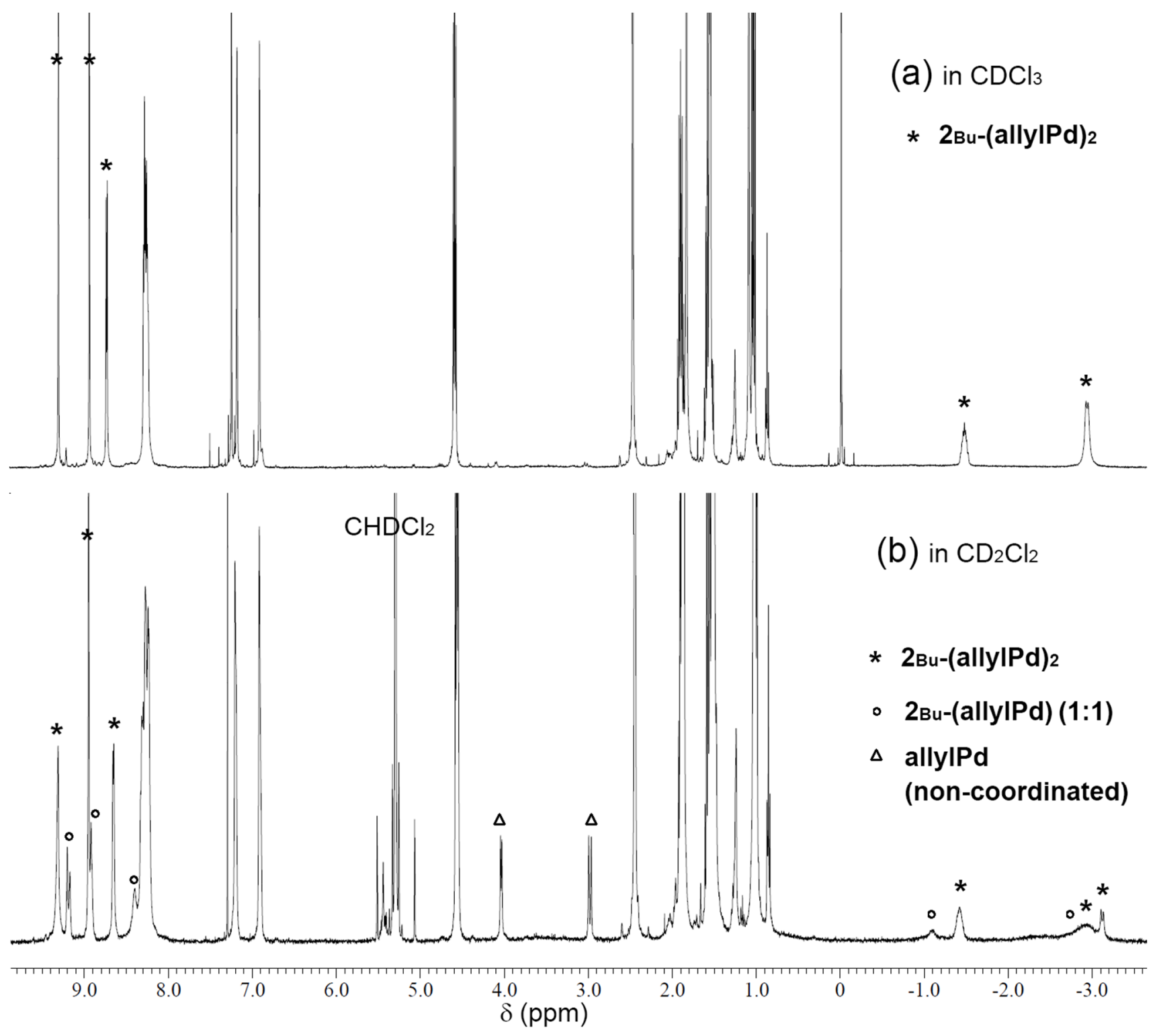

Figure S7. ${ }^{1} \mathrm{H}$ NMR spectra (400 MHz, at rt) of $\mathbf{2}_{\mathbf{B u}}-(\mathbf{a l l y l P d})_{2}$ (purified by recrystallization) in (a) $\mathrm{CDCl}_{3}$ and (b) $\mathrm{CD}_{2} \mathrm{Cl}_{2}$. In (b), $\mathbf{2}_{\mathrm{Bu}}$-(allylPd) $)_{2}: \mathbf{2}_{\mathrm{Bu}}$-(allylPd) $(1: 1$ complex $)=71: 29$. 


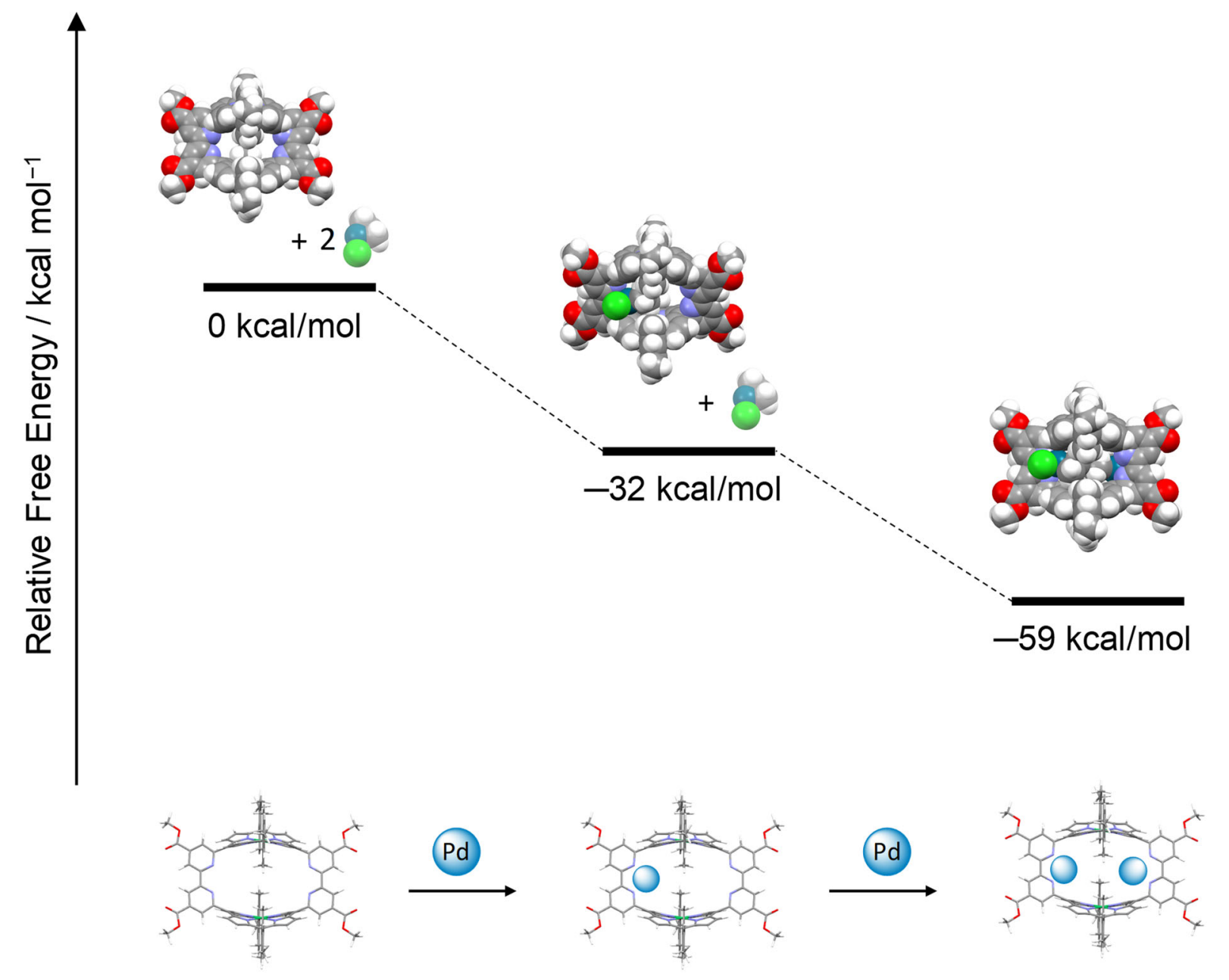

Figure S8. Relative Gibbs free energy profiles of $2^{\mathrm{Me}}$ and the $\eta^{3}$-allylpalladium complexes. The structures were optimized at the B3LYP/LANL2DZ (Ni, Pd)/6-31G(d) $(\mathrm{H}, \mathrm{N}, \mathrm{C}, \mathrm{O}, \mathrm{Cl})$ level in vacuo. 


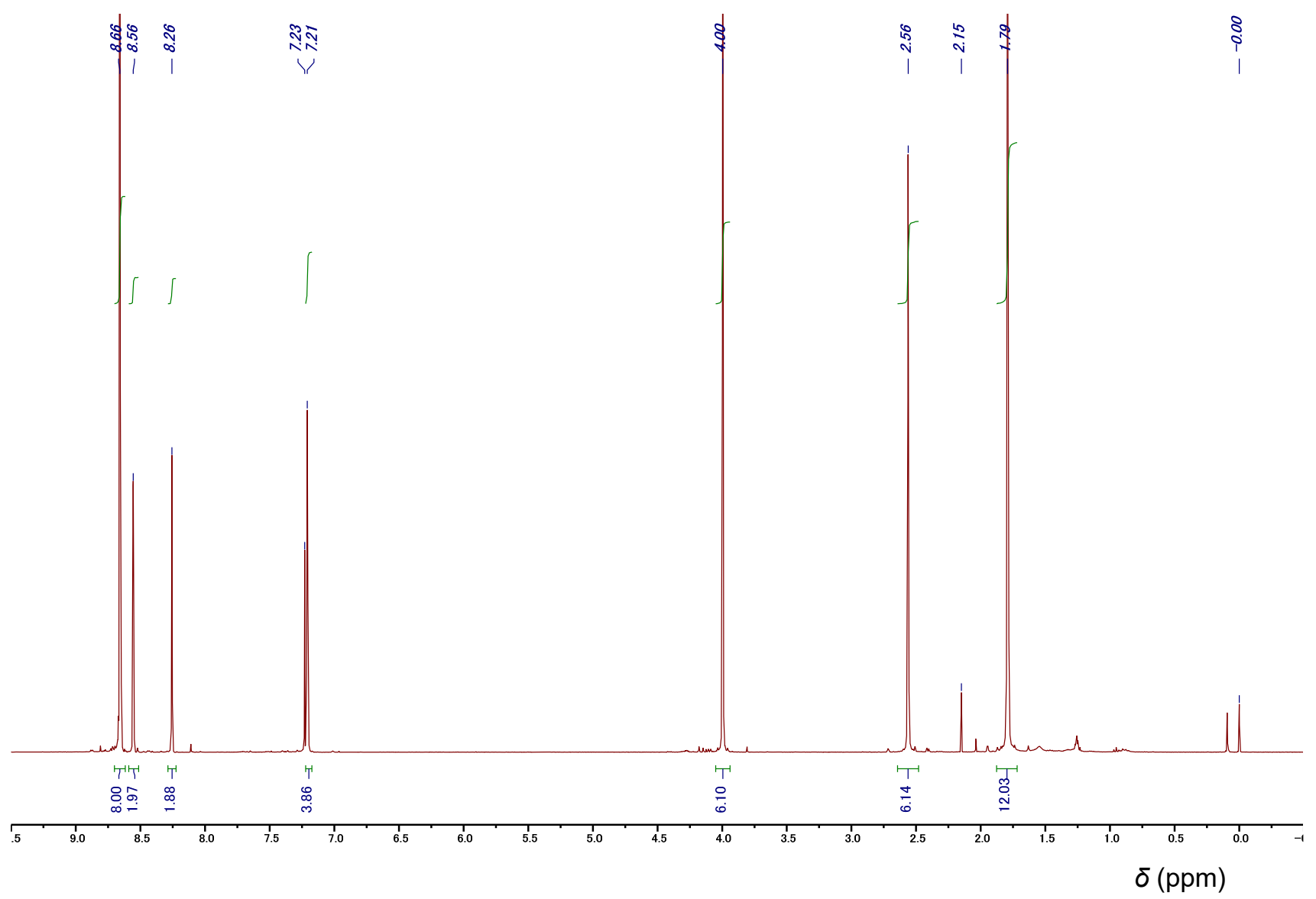

Figure S9. ${ }^{1} \mathrm{H}$ NMR spectrum $\left(400 \mathrm{MHz}, \mathrm{CDCl}_{3}\right)$ of $\mathbf{1}_{\text {Me }}$. 


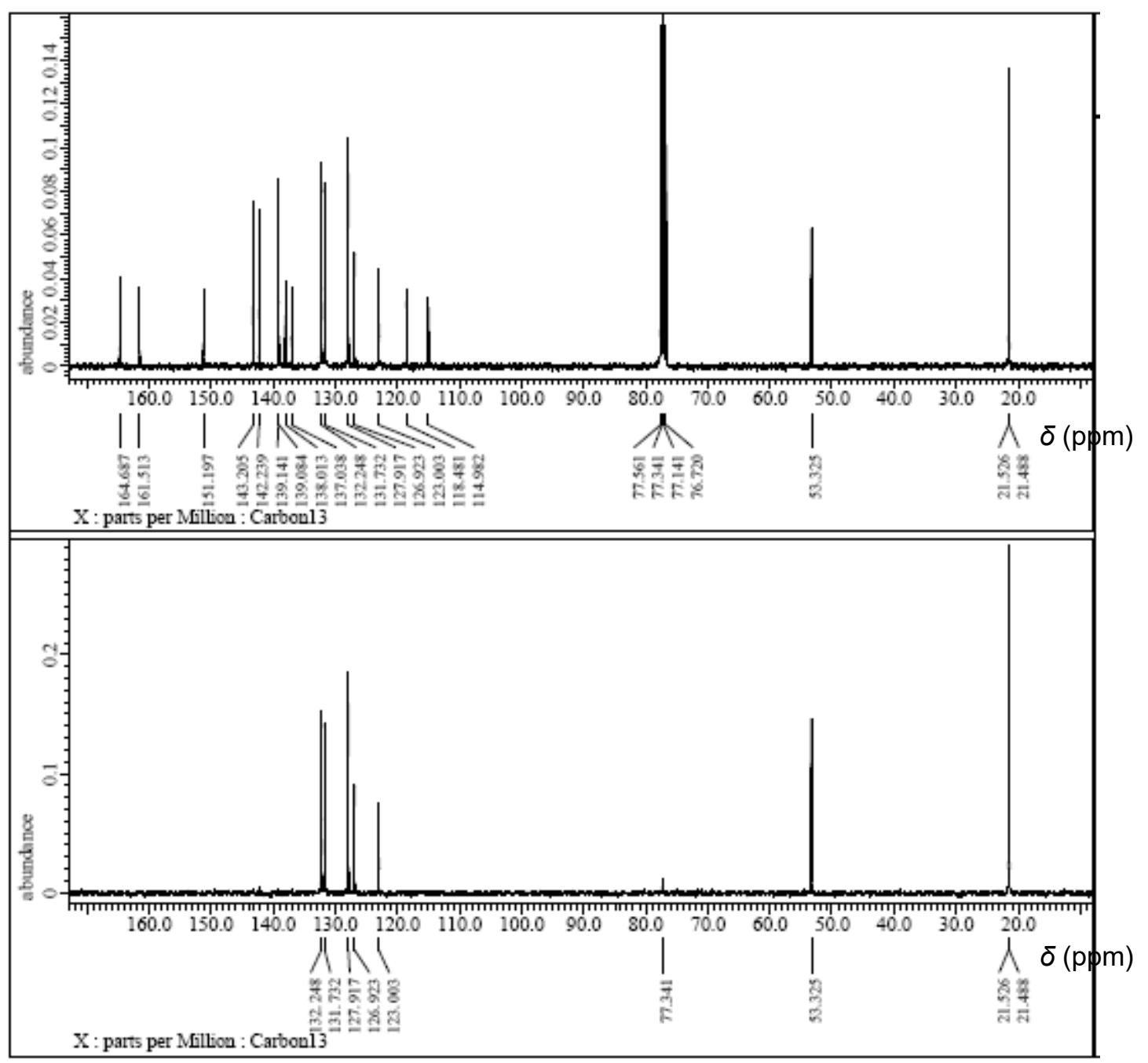

Figure S10. ${ }^{13} \mathrm{C}$ NMR spectrum (upper) and DEPT135 (lower) of $\mathbf{1}_{\mathbf{M e}}\left(100 \mathrm{MHz}, \mathrm{CDCl}_{3}\right)$. 


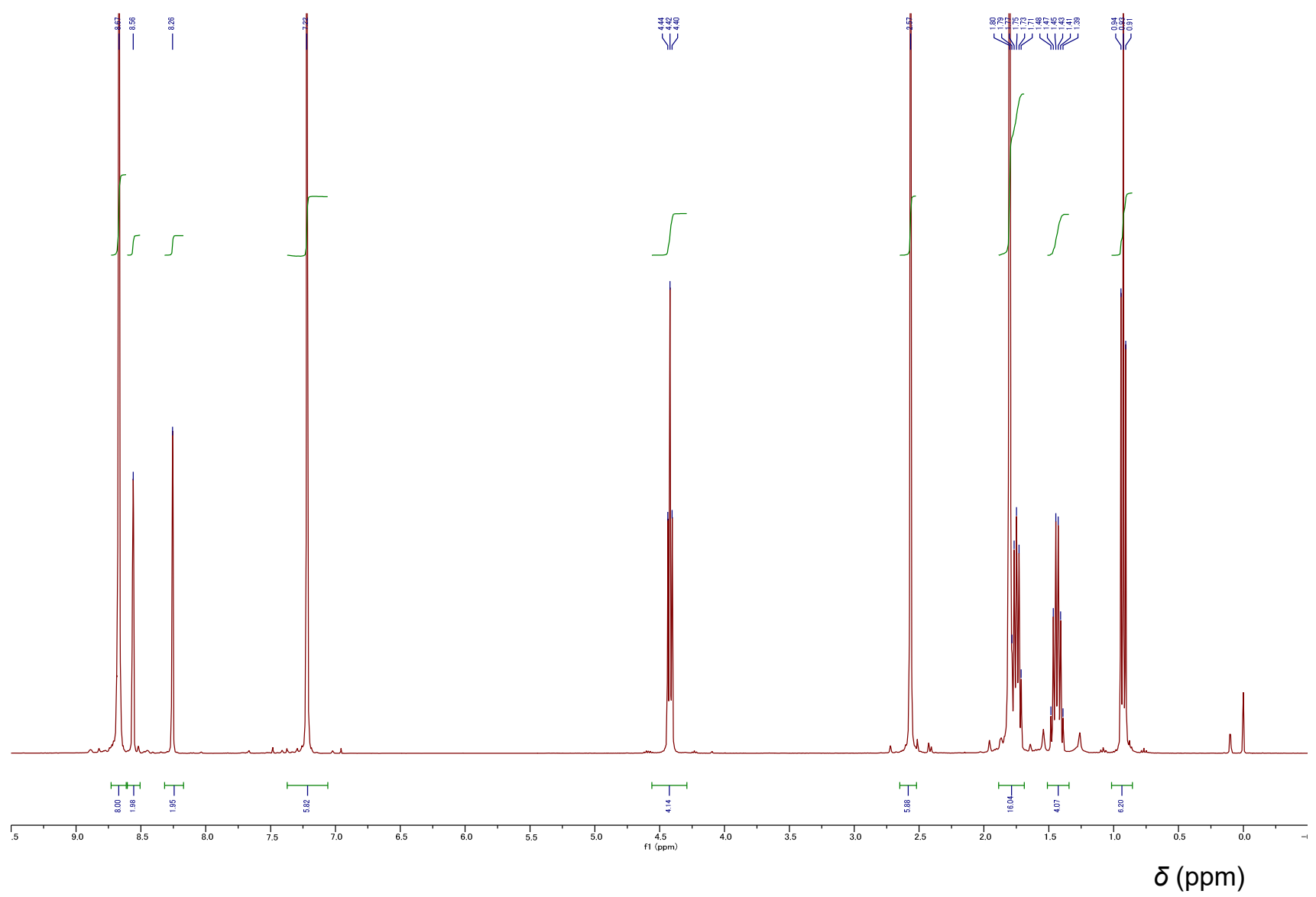

Figure S11. ${ }^{1} \mathrm{H}$ NMR spectrum $\left(400 \mathrm{MHz}, \mathrm{CDCl}_{3}\right)$ of $1_{\mathrm{Bu}}$. 


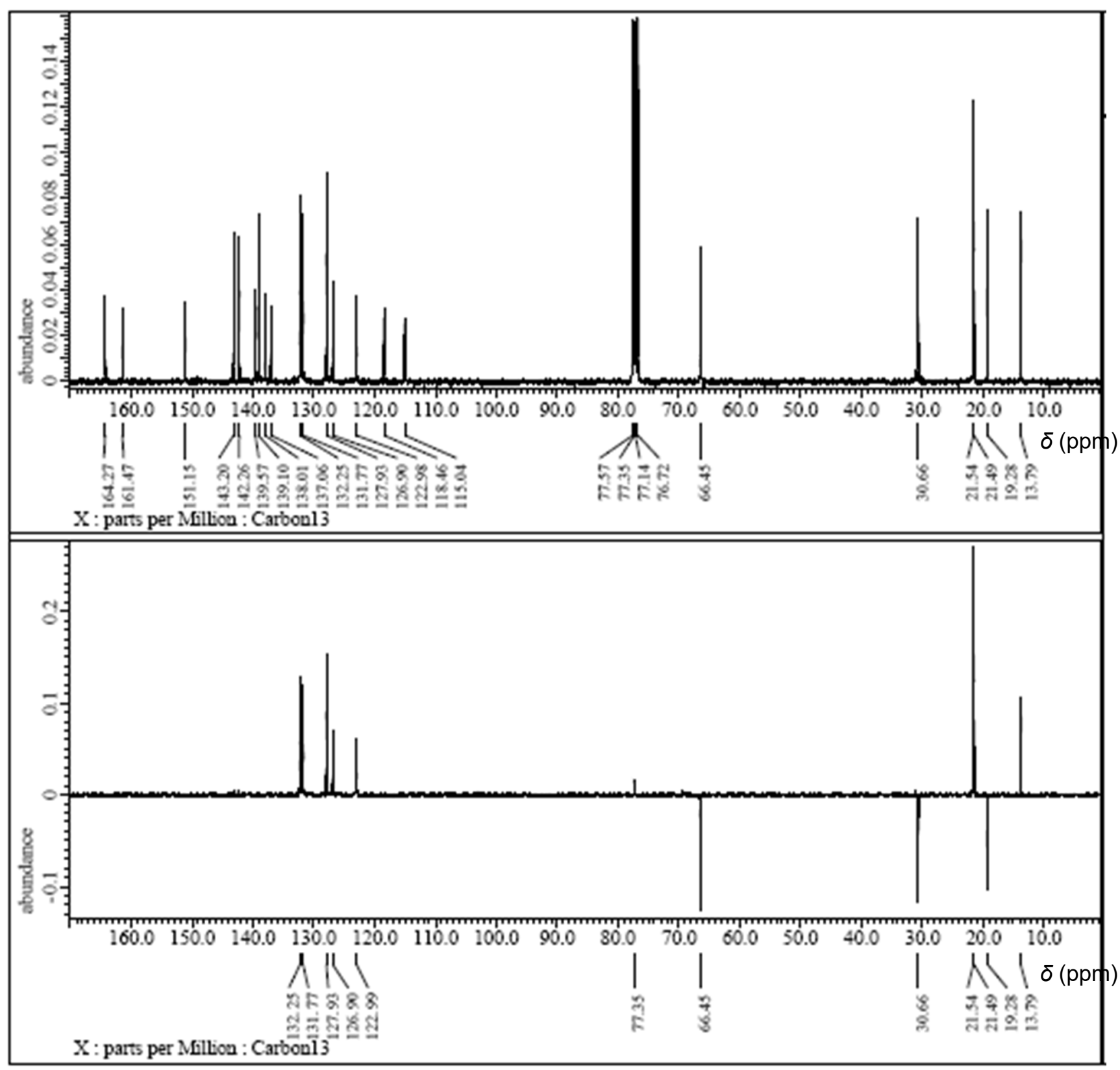

Figure S12. (upper) ${ }^{13} \mathrm{C}$ NMR (100 MHz, $\left.\mathrm{CDCl}_{3}\right)$ of $1_{\mathrm{Bu}}$. (lower) DEPT135. 


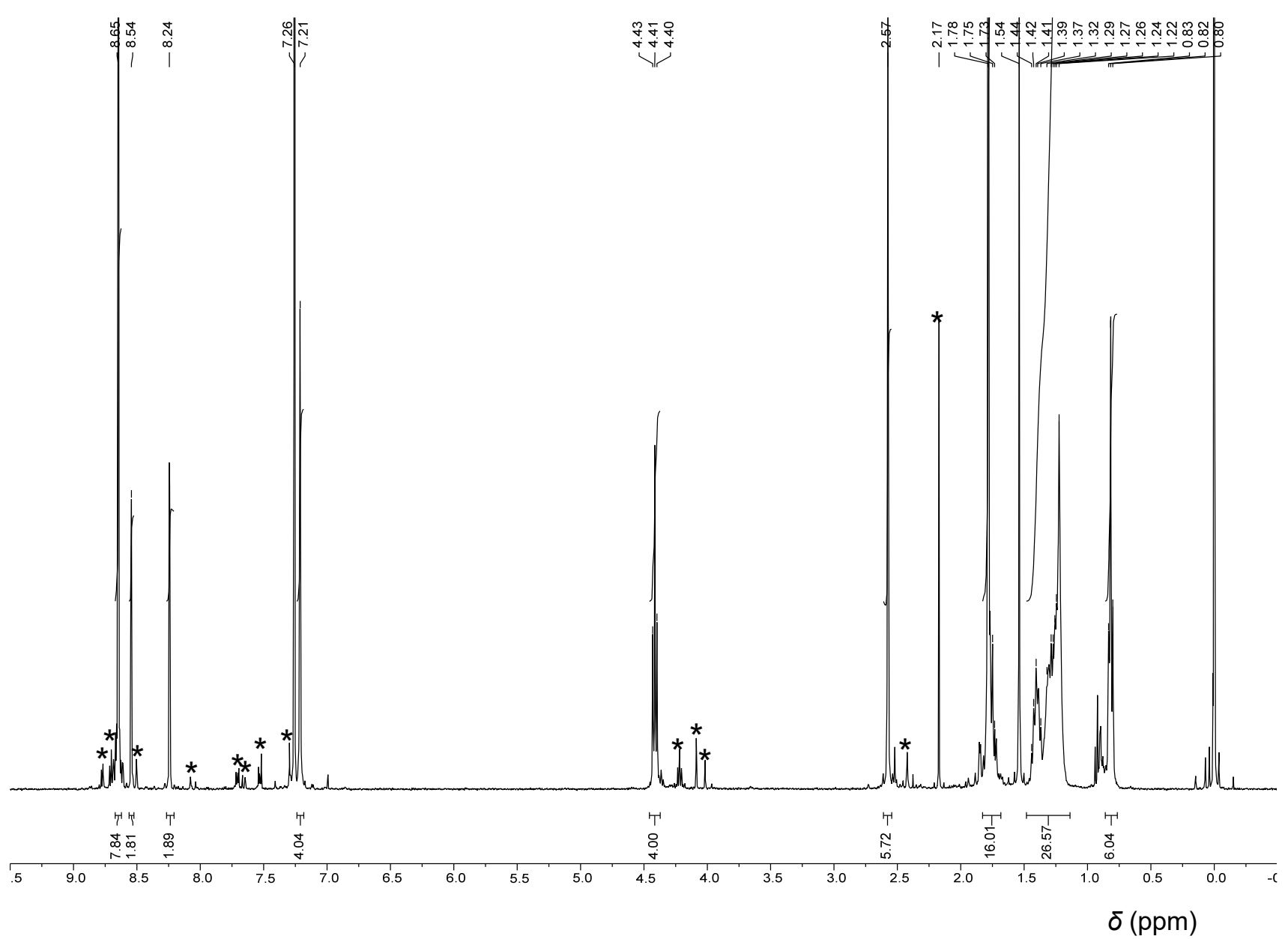

Figure S13. ${ }^{1} \mathrm{H}$ NMR (500 MHz, $\left.\mathrm{CDCl}_{3}\right)$ of $\mathbf{1}_{\text {oc. }}$. The peaks marked as $\left(^{*}\right)$ indicate impurities which can be removed after the homo coupling reaction. 


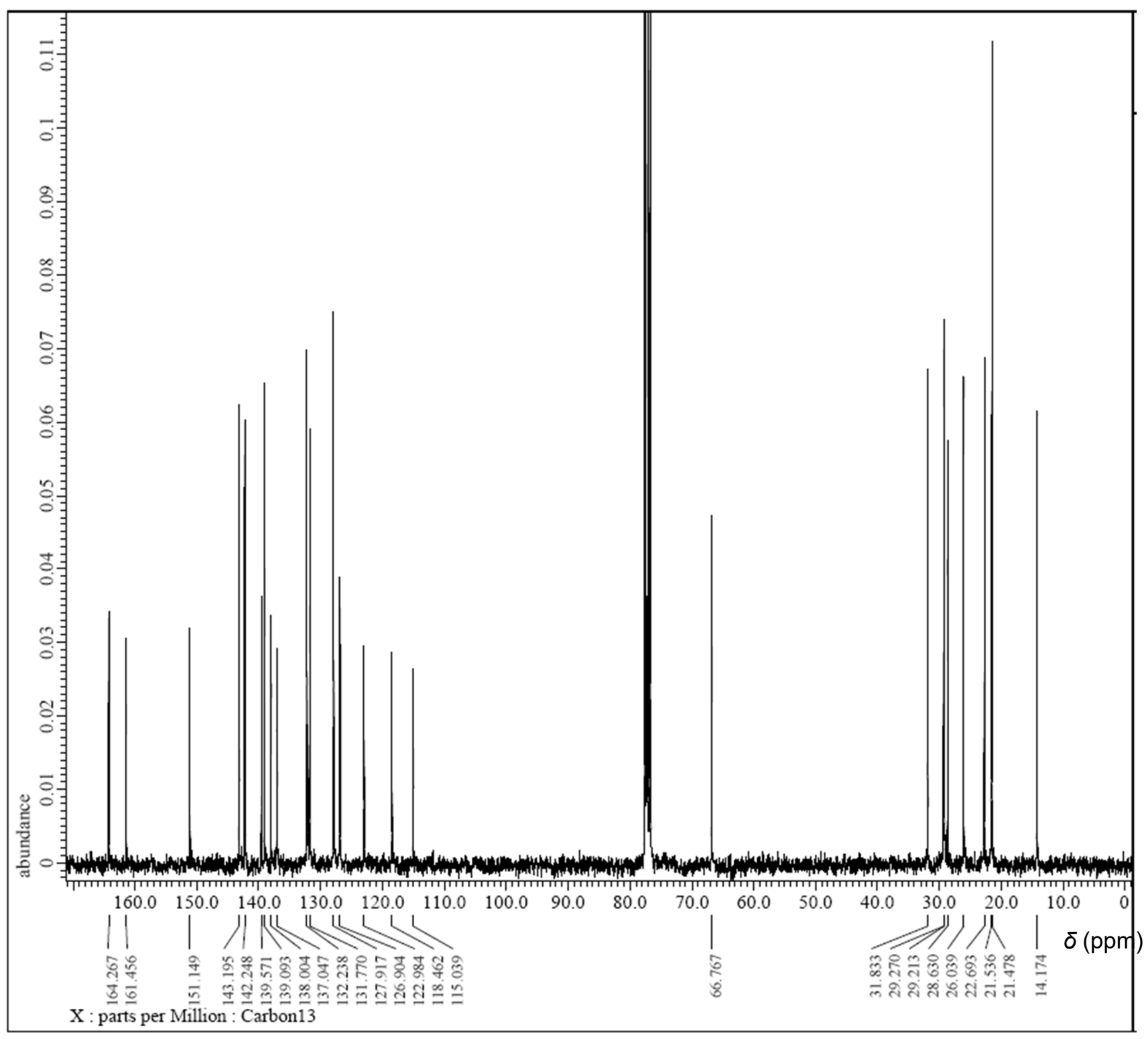

Figure $\mathrm{S} 14 .{ }^{13} \mathrm{C}$ NMR $\left(125 \mathrm{MHz}, \mathrm{CDCl}_{3}\right)$ of $1_{\text {oc. }}$. 


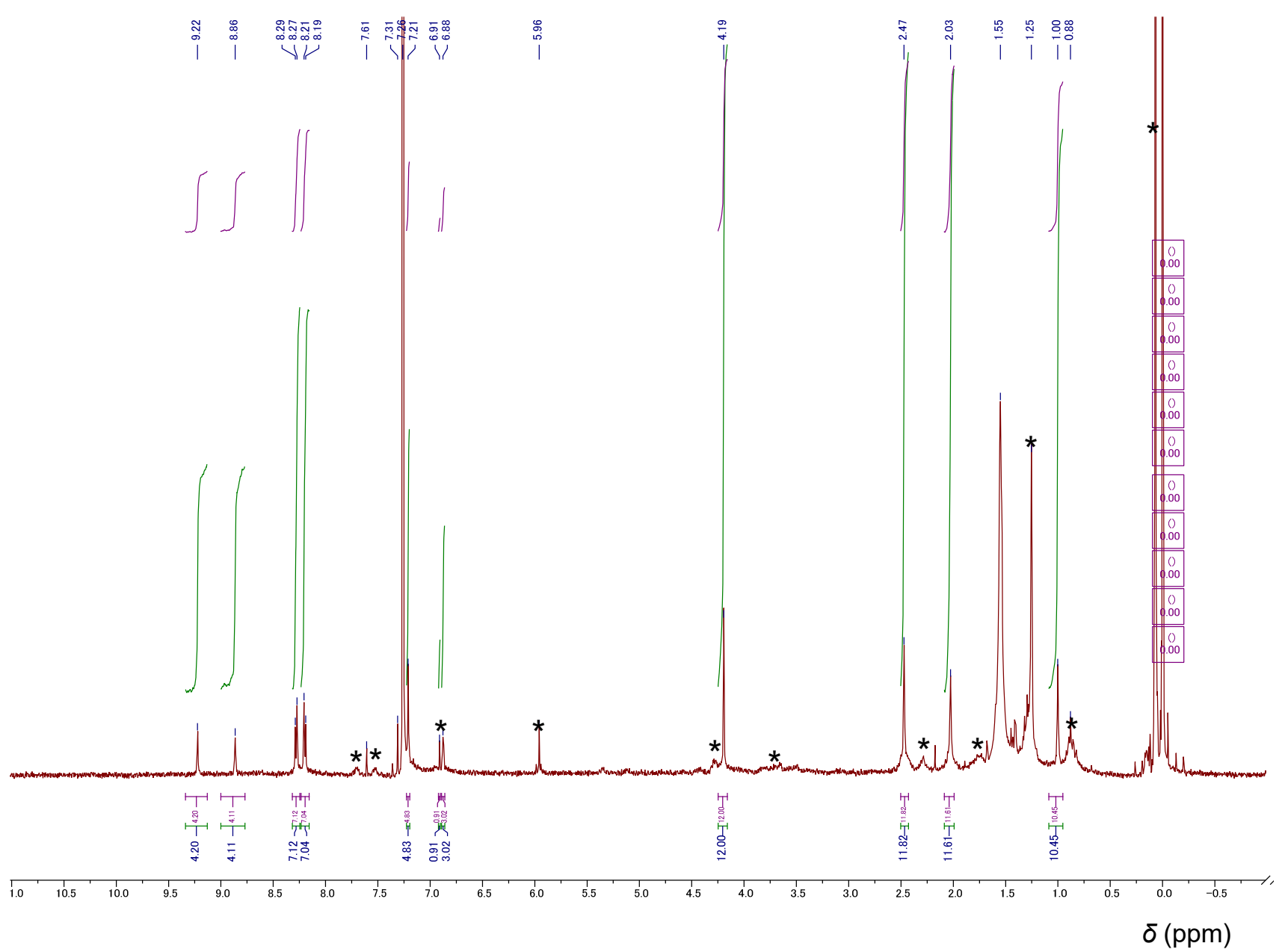

Figure S15. ${ }^{1} \mathrm{H}$ NMR ( $\left.300 \mathrm{MHz}, \mathrm{CDCl}_{3}\right)$ of $\mathbf{2}_{\mathrm{Me}}$. Because compound $\mathbf{2}_{\mathrm{Me}}$ tended to be self-aggregated, the solubility was very low in any solvent. In particular, purified $\mathbf{2}_{\mathrm{Me}}$ was difficult to be measured by ${ }^{1} \mathrm{H}$ NMR. The above ${ }^{1} \mathrm{H}$ NMR spectrum was collected as a roughly purified sample. The peaks marked as $\left(^{*}\right)$ correspond to impurities including other linear oligomers. 


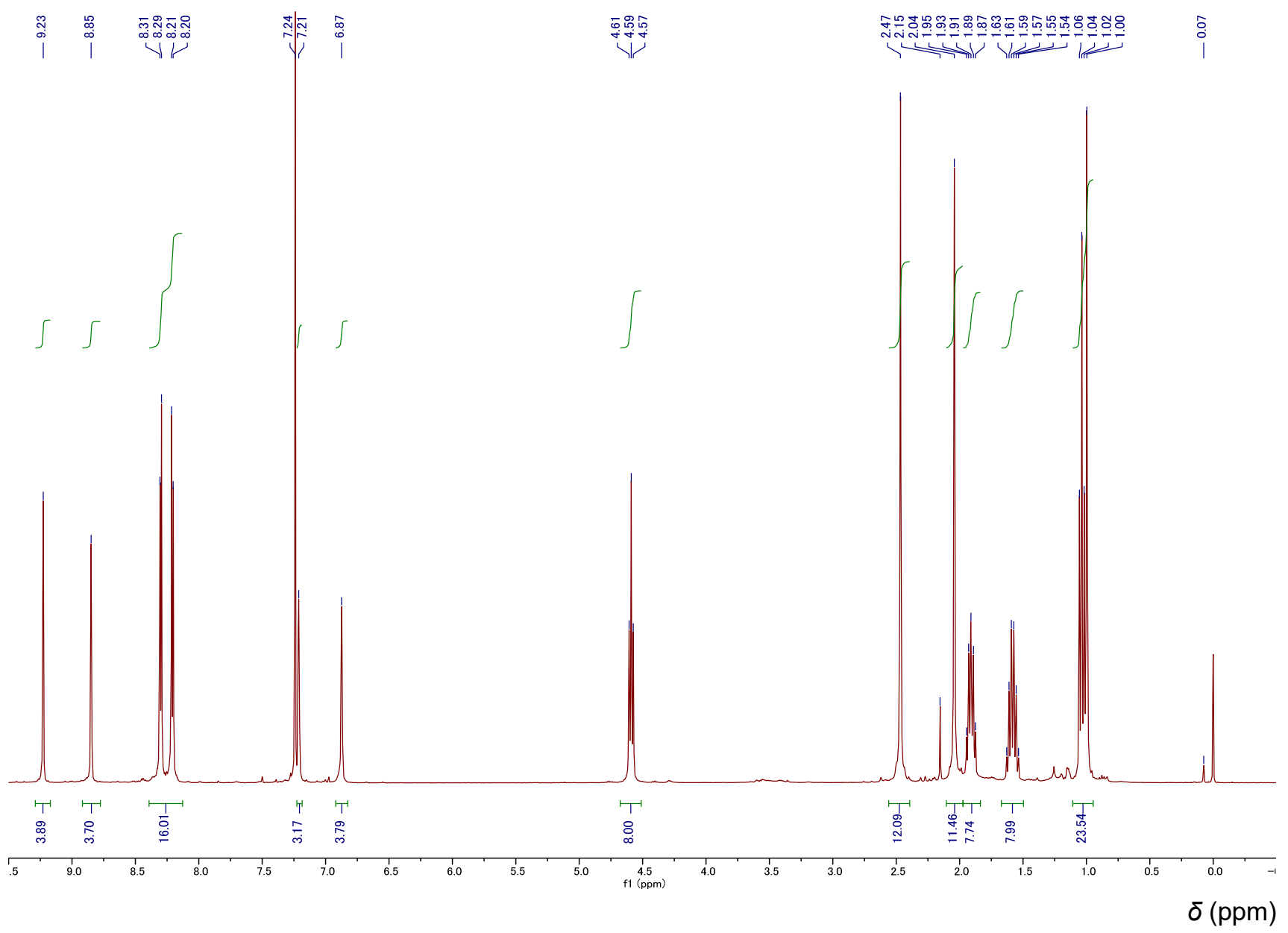

Figure S16. ${ }^{1} \mathrm{H}$ NMR $\left(400 \mathrm{MHz}, \mathrm{CDCl}_{3}\right)$ of $\mathbf{2}_{\mathbf{B u}}$. 

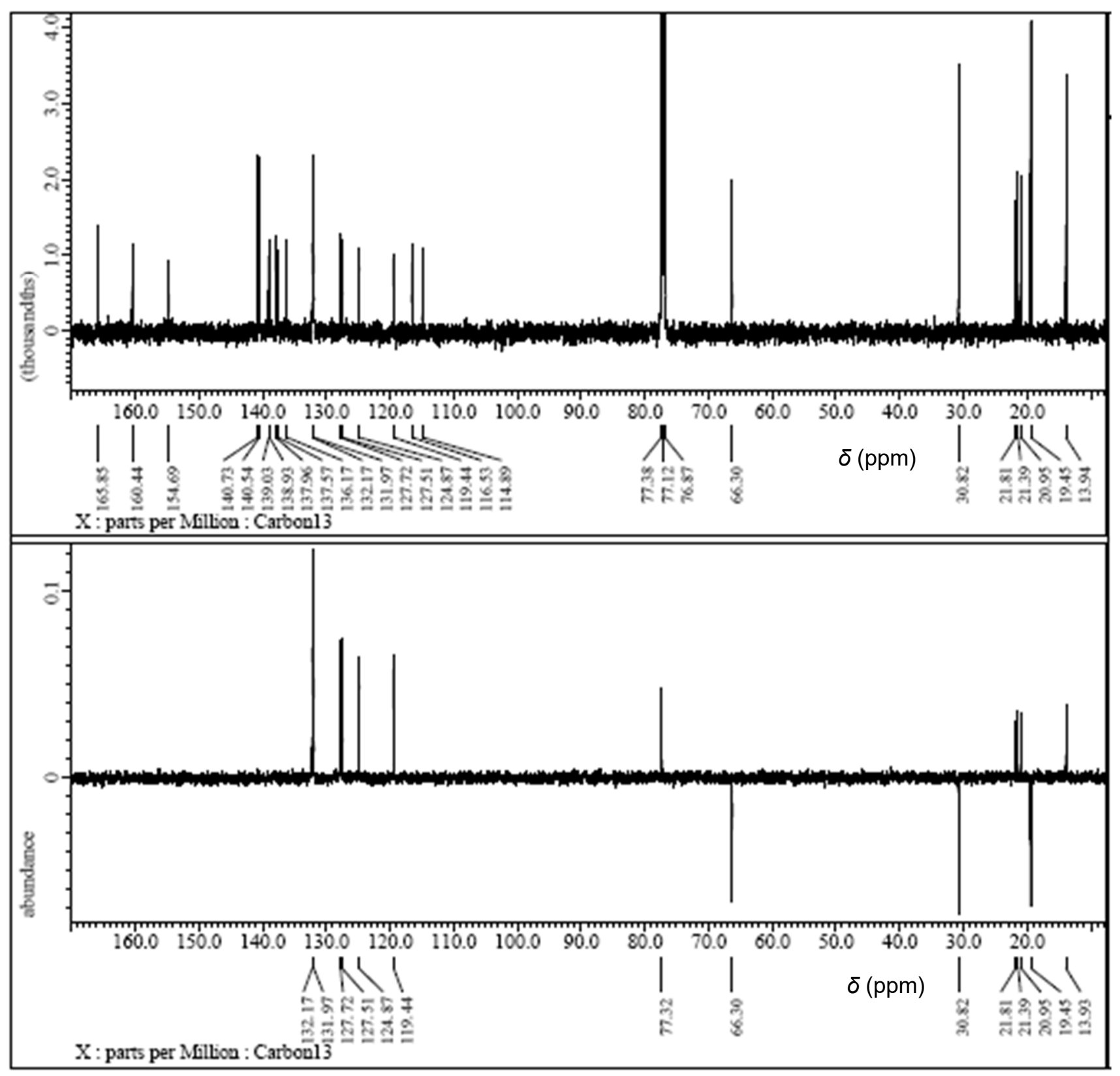

Figure S17. (upper) ${ }^{13} \mathrm{C}$ NMR $\left(100 \mathrm{MHz}, \mathrm{CDCl}_{3}\right)$ of $\mathbf{2}_{\mathrm{Bu}}$. (lower) DEPT135. 


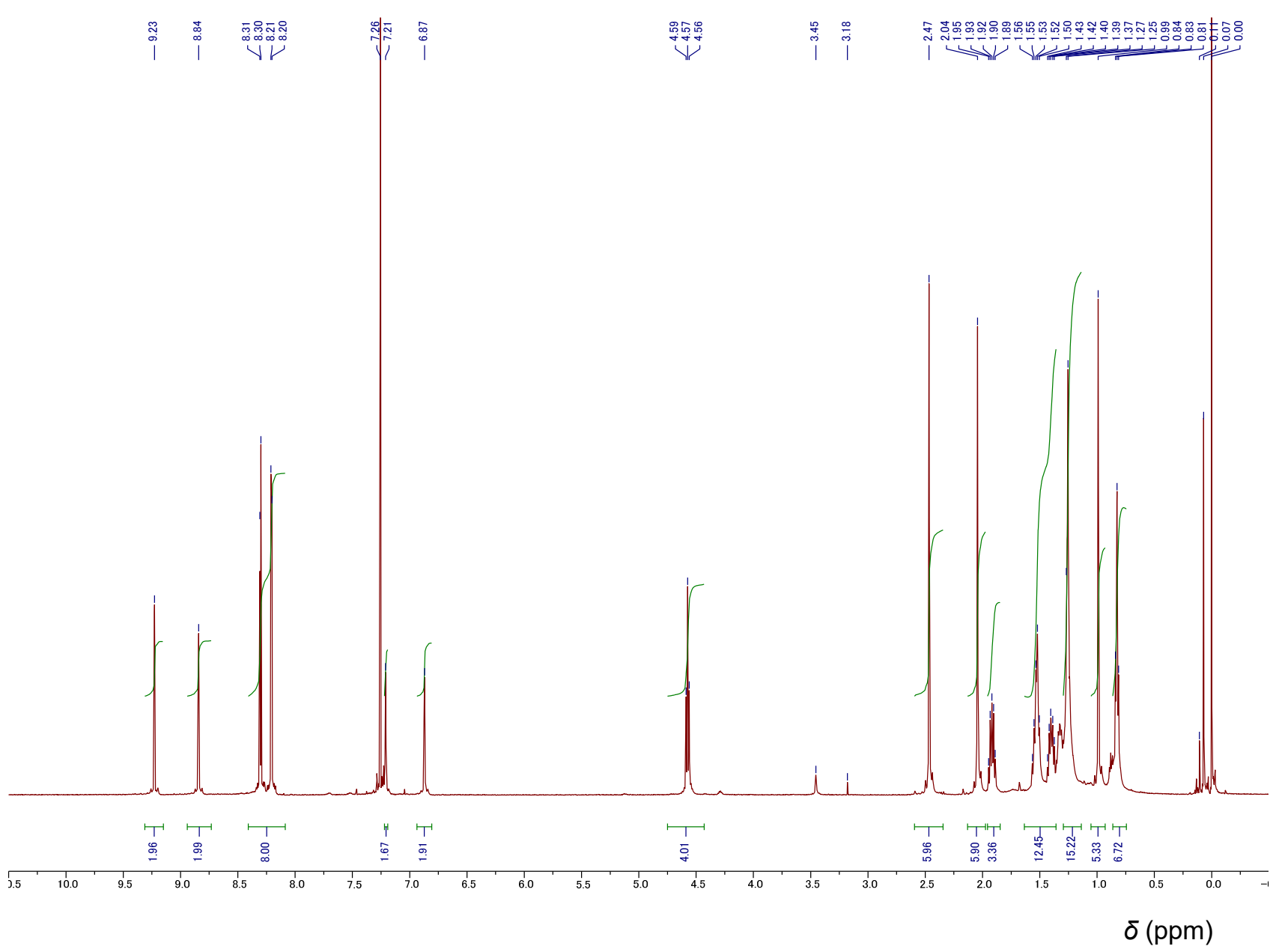

Figure S18. ${ }^{1} \mathrm{H}$ NMR $\left(500 \mathrm{MHz}, \mathrm{CDCl}_{3}\right)$ of $\mathbf{2}_{\mathbf{O}}$. 


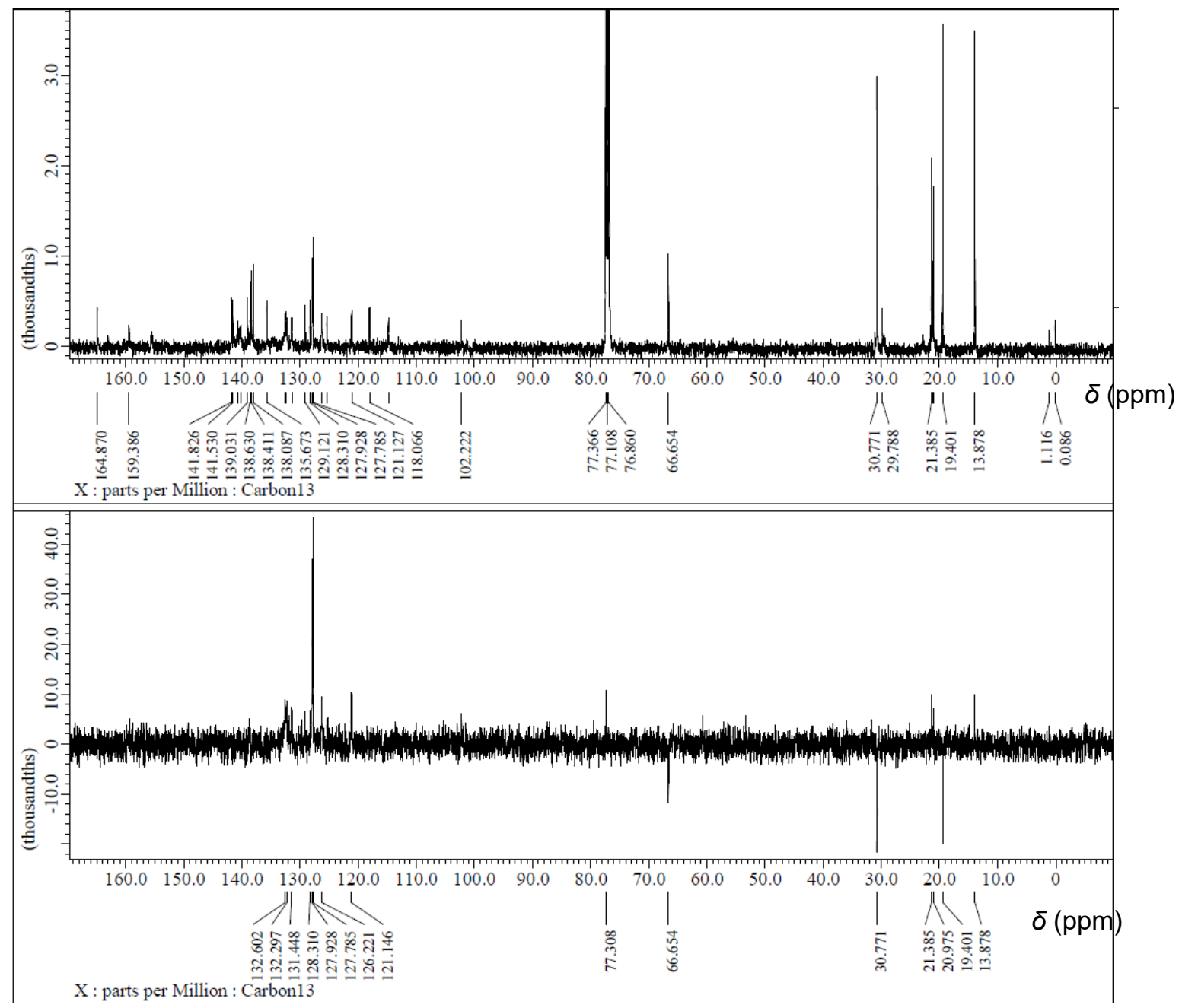

Figure S19. (upper) ${ }^{13} \mathrm{C}$ NMR (125 MHz, $\mathrm{CDCl}_{3}$ ) of $\mathbf{2}_{\mathrm{Bu}}-(\mathbf{a l l y l P d})_{2}$ at $23{ }^{\circ} \mathrm{C}$. (lower) DEPT135.

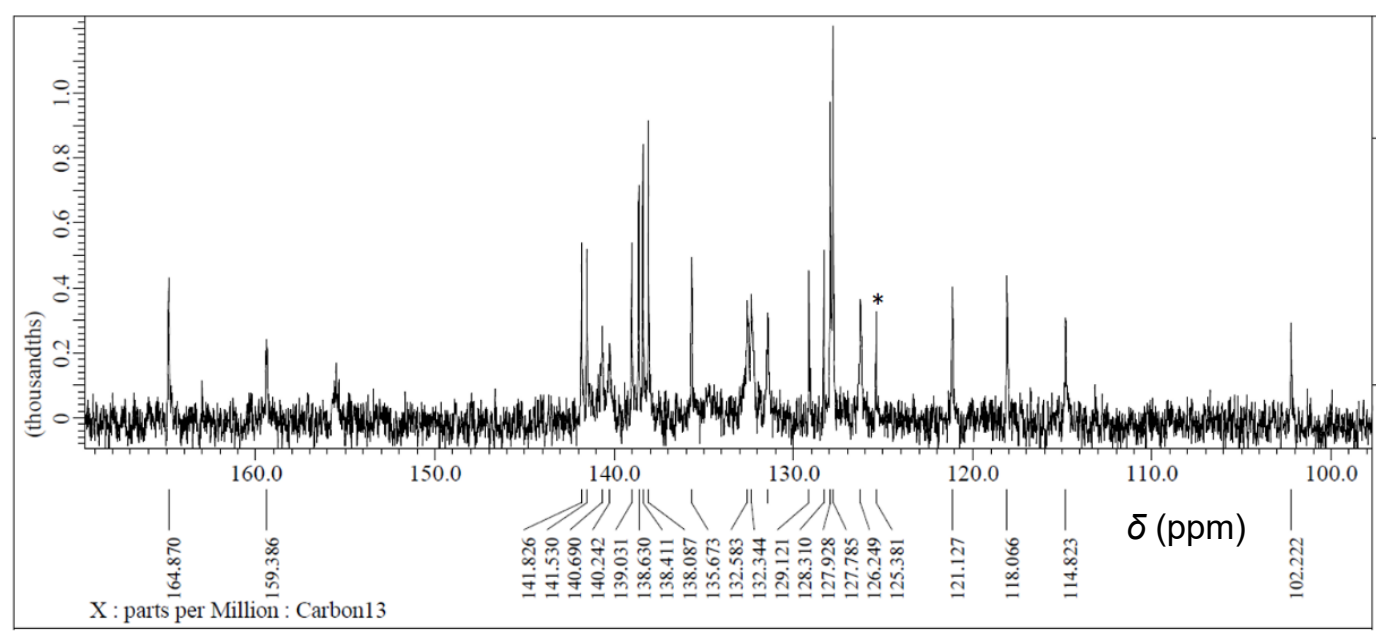

Figure S20. ${ }^{13} \mathrm{C}$ NMR $\left(125 \mathrm{MHz}, \mathrm{CDCl}_{3}\right)$ of $\mathbf{2}_{\mathbf{B u}}-\left(\right.$ allylPd) 2 at $23{ }^{\circ} \mathrm{C}$. (same as Figure $\mathbf{S 1 9}$ (upper) expanded). *: impurity. 


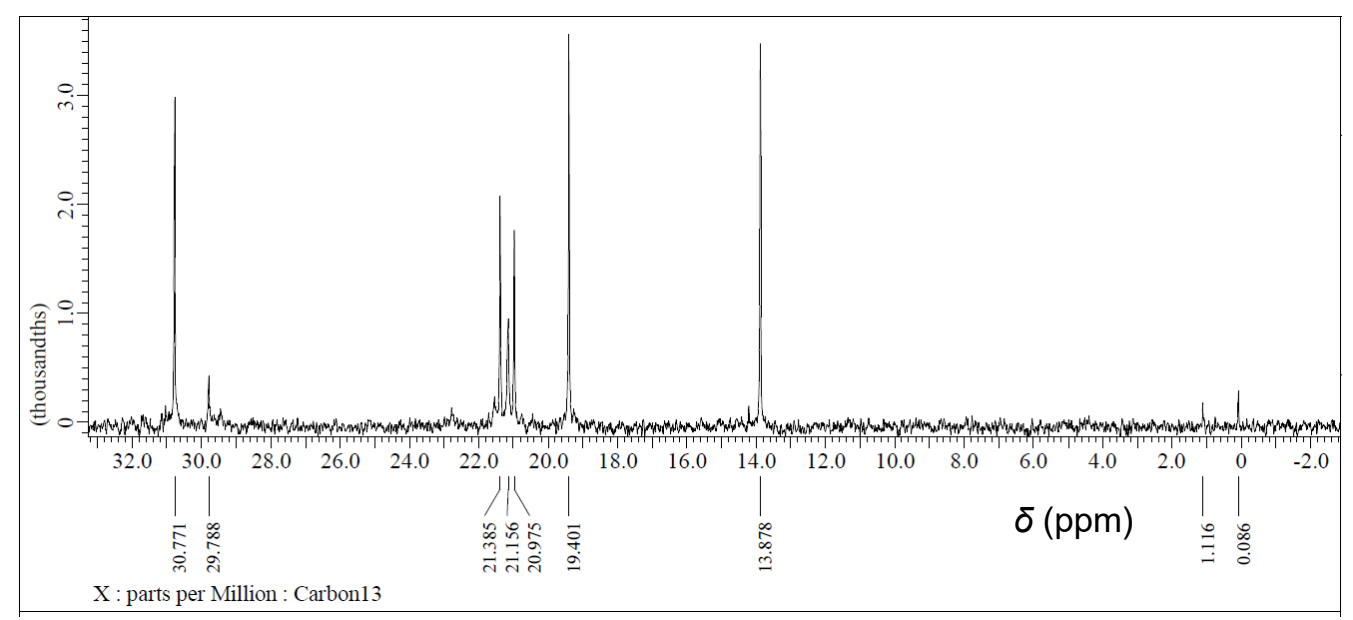

Figure S20. continued.

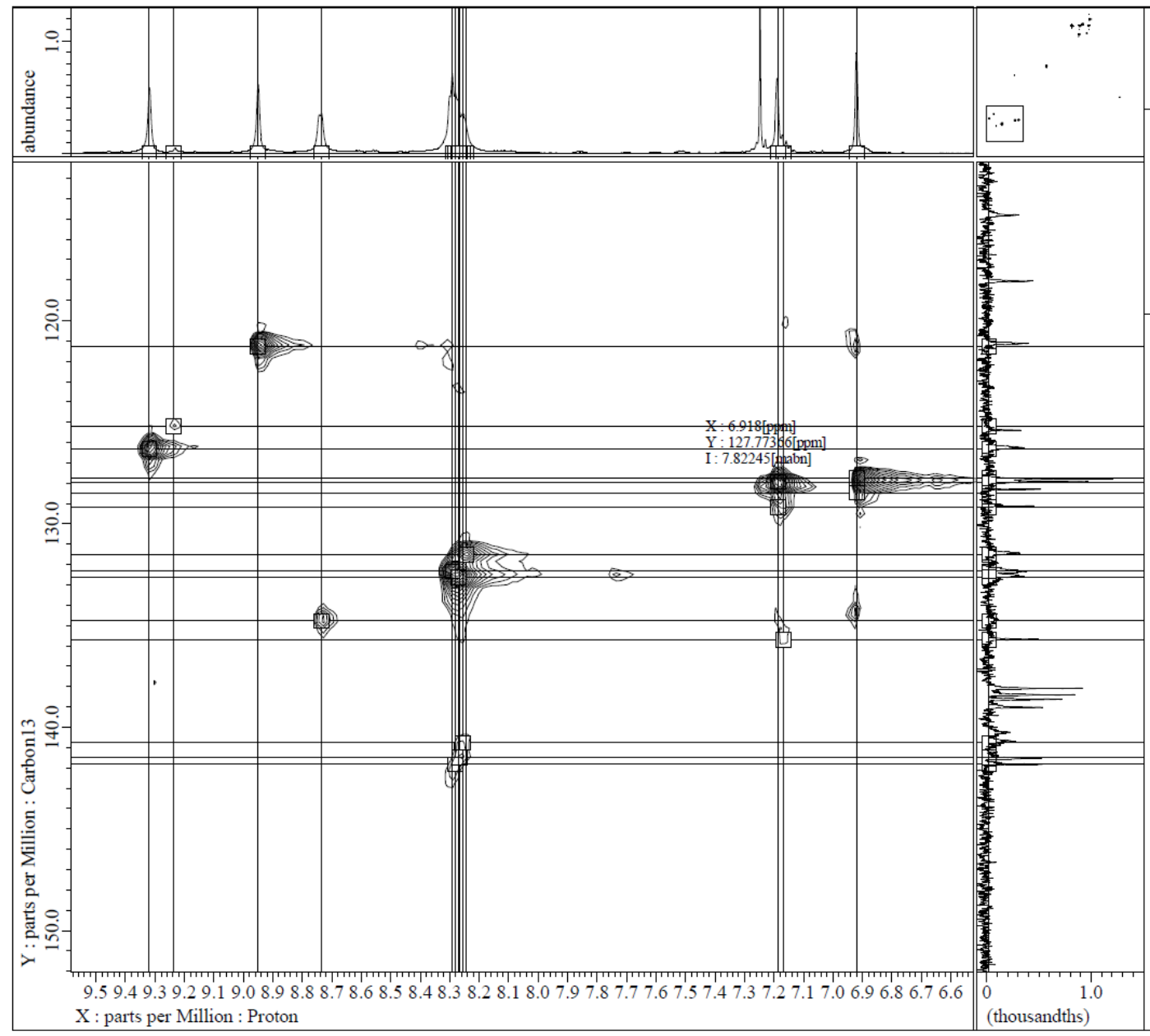

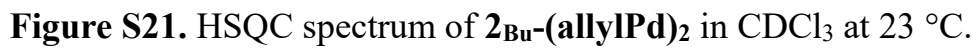




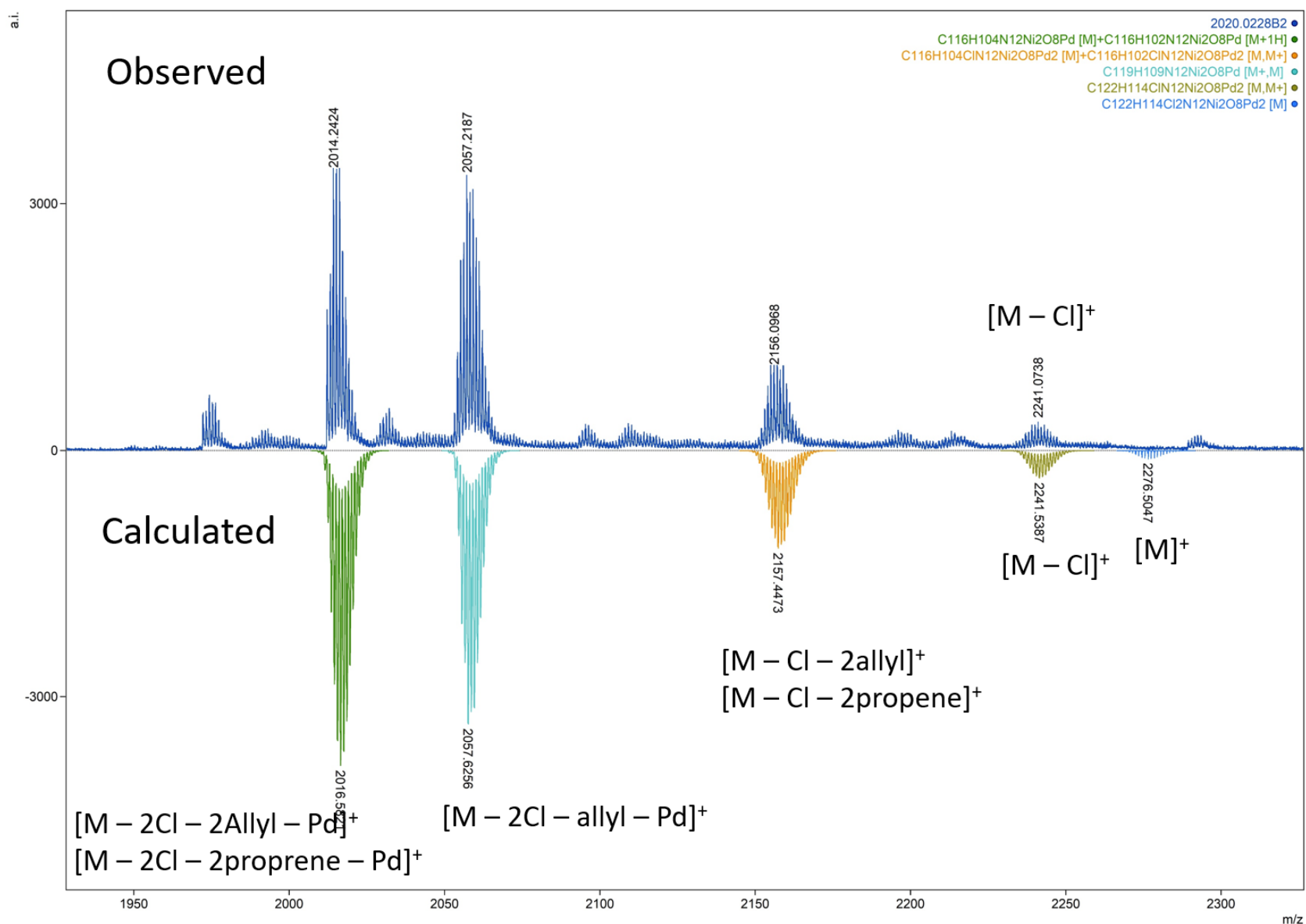

Figure S22. ESI-MS spectrum of $\mathbf{2}_{\mathbf{B u}}-($ allylPd)2. (upward) observed. (downward) calculated. 